\title{
Sleep deprivation reduces the lymphocyte count in a non-obese mouse model of type 1 diabetes mellitus
}

F.S. Ruiz, M.L. Andersen, A. Zager, R.C.S. Martins and S. Tufik
Departamento de Psicobiologia, Escola Paulista de Medicina, Universidade Federal de São Paulo, São Paulo, SP, Brasil

\begin{abstract}
Correspondence
M.L. Andersen

Departamento de Psicobiologia

EPM, UNIFESP

Rua Napoleão de Barros, 925

04024-002 São Paulo, SP

Brasil

Fax: +55-11-5572-5092

E-mail: mandersen@psicobio.epm.br

Research supported by

Associação Fundo de Incentivo à

Psicofarmacologia (AFIP) and FAPESP

(CEPID \#98/14303-3 to S. Tufik).
\end{abstract}

Received August 31, 2006

Accepted January 22, 2007

\begin{abstract}
The objective of the present study was to determine whether sleep deprivation (SD) would promote changes in lymphocyte numbers in a type 1 diabetes model (non-obese diabetic, NOD, mouse strain) and to determine whether SD would affect female and male NOD compared to Swiss mice. The number of lymphocytes in peripheral blood after 24 and $96 \mathrm{~h}$ of SD (by multiple platform method) or equivalent period of time in home-cage controls was examined prior to the onset of diabetes. SD for $96 \mathrm{~h}$ significantly reduced lymphocytes in male Swiss mice compared to control $\left(8.6 \pm 2.1\right.$ vs $\left.4.1 \pm 0.710^{3} / \mu \mathrm{L} ; \mathrm{P}<0.02\right)$. In male NOD animals, 24- and 96-h SD caused a significant decrease of lymphocytes compared to control $(4.4 \pm 0.3 v s 1.6 \pm 0.5 ; \mathrm{P}<0.001$ and $4.4 \pm 0.3$ vs $0.9 \pm 0.110^{3} / \mu \mathrm{L} ; \mathrm{P}<0.00001$, respectively). Both 24 - and 96-h SD induced a reduction in the number of lymphocytes in female Swiss $\left(7.5 \pm 0.5\right.$ vs $4.5 \pm 0.5,4.4 \pm 0.610^{3} / \mu \mathrm{L} ; \mathrm{P}<0.001$, respectively) and NOD mice $\left(4 \pm 0.6\right.$ vs $1.8 \pm 0.2,1.2 \pm 0.410^{3} / \mu \mathrm{L} ; \mathrm{P}<0.01$, respectively) compared to the respective controls. Loss of sleep induced lymphopenia in peripheral blood in both genders and strains used. Since many cases of autoimmunity present reduced numbers of lymphocytes and, in this study, it was more evident in the NOD strain, our results suggest that SD should be considered a risk factor in the onset of autoimmune disorders.
\end{abstract}

The non-obese diabetic (NOD) mouse spontaneously develops type 1 diabetes mellitus that has many similarities to the human type 1 diabetes. This strain has become particularly useful as an important model of autoimmune disease which typically results from the deregulation of fundamental processes designed to maintain self-tolerance. Type 1 diabetes occurs as a consequence of progressive destruction of pancreatic $\beta$ cells
Key words

- Sleep deprivation

- Stress

- Lymphopenia

- Diabetes

- Non-obese diabetic mouse

- Swiss mice

.................... by autoimmune T-cells (1).

Of particular interest is the fact that a significant portion of the conditions that lead to type 1 diabetes occurs in the presence of a reduced number of immune cells or lymphocytes (lymphopenia) (2). It is a fact that animal models of autoimmunity often involve the induction of lymphopenia by genetic or experimental means (3). Type 1 diabetes occurs earlier and more often in 
female mice, with prevalence reaching 30 to $70 \%$ compared to males, in which the overall incidence remains under $20 \%$ (4). Moreover, the prevalence of diabetes may also vary depending upon environmental factors like stress.

The close association of stress and sleep deprivation (SD) can be viewed as the outcome of the pressure exerted by society on an individual with repercussions on his health and well-being. Indeed, SD is an inherently stressful procedure, and all SD techniques involve some degree of stress. Nevertheless, sleep is essential for the recovery from illness and, conversely, lack of sleep impairs host defense (5). SD is a condition that is now perceived to have some influence on the proper functioning of host defense systems.

An association between sleep duration and increased risk of developing diabetes has been reported by several investigators (6). However, further research is needed to elucidate this association, and to determine whether the etiology of habitual short sleeping time affects long-term health (7). In this context, a recent study demonstrated that the alterations occurred during SD suggest an activation of nonspecific immune parameters on the short-term periods (e.g., SD for 24 and $96 \mathrm{~h}$ ) and a significant impairment of cellular response during long-term sleep restriction (Zager A, Andersen ML, Ruiz FS, Antunes IB, Tufik S, unpublished results).

Thus, the objective of the present study was to first assess whether loss of sleep, as a stressor, could induce changes in circulating peripheral lymphocytes in a type 1 diabetes model strain, and then to determine whether SD could exert different influences on female and male NOD mice.

Three-month-old male and female Swiss and NOD mice were obtained from CEDEME (UNIFESP). The study was conducted in accordance with the Ethics and Practical Principles of the Use of Laboratory Animals. The minimum number of animals was used to obtain statistically meaningful results and all attempts were made to mitigate any suffering. Since NOD mice are susceptible to the development of autoimmune disorders, we extended our study by comparing the effects of SD on a normal strain (Swiss mice).

Naive male and female mice were distributed randomly into two groups: homecage control and SD groups, according to gender and strain. Based on previous studies, the SD groups were subjected to SD for 24 or $96 \mathrm{~h}$ (8). According to VelazquezMoctezuma et al. (9), $24 \mathrm{~h}$ of SD significantly decrease the total number of lymphocytes in rats. The experimental groups were submitted to SD using the modified multiple platform method, which consists of placing 5 mice inside cages $(38 \times 31 \times 17 \mathrm{~cm})$ containing 14 circular platforms $(3.5 \mathrm{~cm}$ in diameters) with water up to $1 \mathrm{~cm}$ of their upper surface. At the onset of each paradoxical sleep episode, the animal experiences a loss of muscle tonus and falls into the water, thus awakening. Food and water were available ad libitum.

After being housed in the water cages (SD groups) or home-cages (control group), mice were brought to an adjacent room and decapitated at 9:00 am and at noon. Differential leukocyte counts were determined in blood using an automatic blood cell counter (Advia 120 Hematology System, Tarrytown, NY, USA) on the same day.

The lymphocyte counts of the control and SD groups of both sexes are reported as means \pm SEM and were analyzed by the Student $t$-test to compare differences between groups. The level of significance was set at $\mathrm{P}<0.05$.

SD for $96 \mathrm{~h}$ significantly reduced lymphocytes in male Swiss mice compared with control $\left(8.6 \pm 2.1\right.$ vs $4.1 \pm 0.710^{3} / \mu \mathrm{L} ; \mathrm{P}<$ 0.02 , Figure 1A), and 24- and 96-h SD significantly reduced lymphocytes in NOD mice compared to control ( $4.4 \pm 0.3$ vs $1.6 \pm 0.5$; $\mathrm{P}<0.001$ and $4.4 \pm 0.3$ vs $0.9 \pm 0.110^{3 / \mu L}$; 
$\mathrm{P}<0.00001$, respectively). After $96 \mathrm{~h}$ of SD, lymphocytes were reduced by $79.5 \%$ compared to control $\left(4.4 \pm 0.3\right.$ vs $0.9 \pm 0.110^{3} /$ $\mu \mathrm{L} ; \mathrm{P}<0.00001)$. Further analyses were conducted to compare Swiss and NOD mice. The Student $t$-test revealed that lymphocytes were significantly reduced in the NOD strain in both SD groups compared to Swiss mice at the same times of $\mathrm{SD}(24 \mathrm{~h}: 7.1 \pm 1.0 v s 1.6$ \pm 0.5 and $96 \mathrm{~h}: 4.1 \pm 0.7$ vs $0.9 \pm 0.110^{3} / \mu \mathrm{L}$; $\mathrm{P}<0.001$, respectively). Among controls, the differences between groups were not statistically significant.

In female Swiss mice, both 24-h and 96$\mathrm{h}$ SD induced a significant reduction in lymphocytes compared to control $(7.5 \pm 0.5 v s$ $4.5 \pm 0.5,4.4 \pm 0.610^{3} / \mu \mathrm{L} ; \mathrm{P}<0.001$, respectively, Figure 1B). Similar results were observed for NOD mice, with animals submitted to 24- and 96-h SD differing from their respective controls $(4 \pm 0.6$ vs $1.8 \pm 0.2$, $1.2 \pm 0.410^{3} / \mu \mathrm{L} ; \mathrm{P}<0.01$, respectively). In the 96-h SD NOD group, the reduction in lymphocytes reached $70 \%$ compared to control $\left(4.0 \pm 0.6\right.$ vs $\left.1.2 \pm 0.410^{3} / \mu \mathrm{L} ; \mathrm{P}<0.01\right)$. The Student $t$-test indicated that for all conditions [control $\left(7.5 \pm 0.5 v s 4.0 \pm 0.610^{3 /}\right.$ $\mu \mathrm{L} ; \mathrm{P}<0.001)$ and $24-(4.5 \pm 0.5$ vs $1.8 \pm 0.2$ $\left.10^{3} / \mu \mathrm{L} ; \mathrm{P}<0.001\right)$ or $96-\mathrm{h}(4.4 \pm 0.6$ vs $1.2 \pm$ $\left.0.410^{3} / \mu \mathrm{L} ; \mathrm{P}<0.01\right) \mathrm{SD}$ ] the lymphocyte counts of NOD animals were significantly decreased compared to the Swiss strain.

We examined the effects of a short $(24 \mathrm{~h})$ and prolonged (96 h) SD period on the profile of peripheral lymphocytes and found that SD was effective in markedly reducing the number of lymphocytes in NOD mice of both genders. In contrast, control NOD males did not differ significantly from control Swiss mice, whereas NOD females showed a significant reduction in lymphocytes compared to control Swiss mice. When submitted to the SD paradigm, regardless of the duration of sleep loss, both genders of the NOD strain had significantly less lymphocytes than their respective control groups. In Swiss males, 24-h SD did not induce any changes and a 4- day SD period was required to significantly reduce lymphocytes. In females, a significant decrease in the number of lymphocytes was observed already after $24 \mathrm{~h}$ of SD, with low counts remaining during the 96-h SD period. Considering the results as a whole, lymphopenia was more evident in the NOD strain.

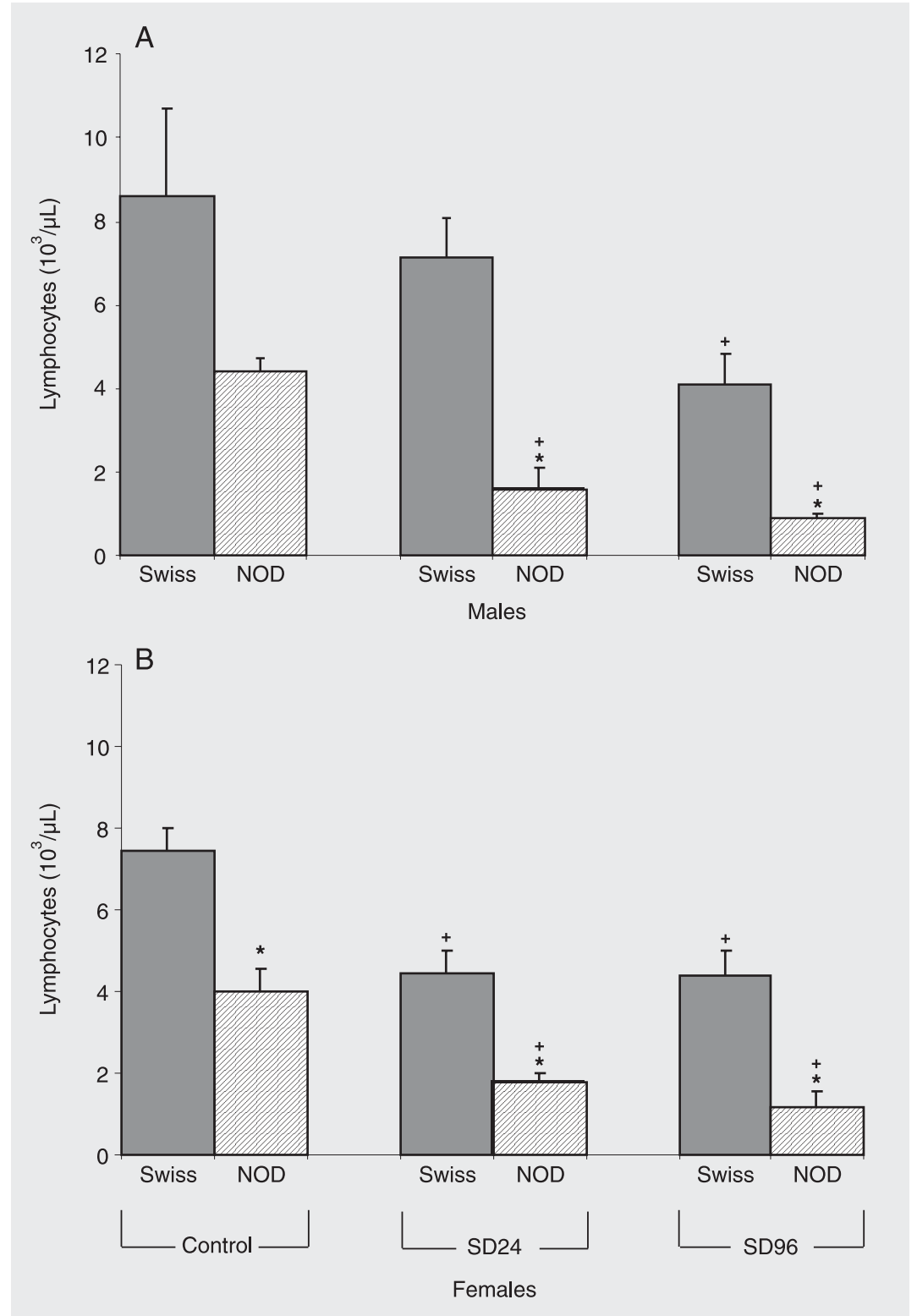

Figure 1. Effect of sleep deprivation for 24 and $96 \mathrm{~h}$ on the lymphocyte count of male (panel A) and female (panel B) non-obese diabetic (NOD) and Swiss strain mice submitted to sleep deprivation for 24 (SD24) and $96 \mathrm{~h}$ (SD96) or maintained as home-cage control. Data are reported as means \pm SEM for 4-8 animals per group. ${ }^{*} P<0.05$ compared to Swiss mice; ${ }^{+} P$ $<0.05$ compared to the control group of each strain (Student $t$-test). 
Many studies have been performed to address the nature of the deficiencies that lead to autoimmunity. The focus of such investigations has been on the lack of immune regulatory cells such as lymphocytes. Lymphopenia, measured by quantifying lymphoid cells, has been recognized as a condition that drives the development of autoimmunity (3). In humans, several autoimmune diseases, including insulin-dependent diabetes mellitus, are detected in association with lymphopenia (10).

SD is an inherently stressful condition that is increasingly ubiquitous in many countries. It may not be possible to completely extricate the effects of SD from those produced by general stress. Additionally, SD is considered to be a health risk factor that contributes to several disease processes (11) and leads to behavioral $(12,13)$ and hormonal alterations $(8,14)$. All of these variables are known to alter the immune response. One of the most compelling findings suggesting that SD compromises host defense is the increased rate of bacteremia in chronically sleep-deprived rats (15). The observation of infection in healthy tissue of sleepdeprived subjects leads one to believe that SD negatively affects the immune response, rendering such subjects more prone to disease and to the exacerbation of pre-existing conditions.

Our data demonstrate that even a short SD period may promote reduction in the number of lymphocytes, an immune parameter considered to be essential for the proper function of the host defense. Lymphopenia was observed in both healthy (Swiss) and NOD animals. It has been shown that housing conditions and degree of emotionality interfere with the incidence of diabetes (16). In Swiss females sleep deprived for $24 \mathrm{~h}$, we observed a significant decrease in the number of lymphocytes which remained at low counts during the $96 \mathrm{~h}$ of SD, corroborating the effect of SD on steroid hormones in the female reproductive system (13). NOD males are more emotional than NOD females and the less emotional NOD females become diabetic earlier, suggesting that emotionality via neuroendocrine alterations may be a mediating factor that modulates the expression of diabetes (17). Despite the existence of evidence that SD is detrimental to immunological function, to our knowledge, this is the first study that reports the effect of different schedules of SD on a type 1 diabetic strain compared to a non-diabetic strain. The SD paradigm was applied prior to the onset of diabetes, usually occurring between the 12 th and 30th week of age (18).

Our study complements and extends other investigations of gender response to SD (13). In contrast to males, NOD female mice did present lymphopenia, possibly induced by survival mechanisms of disrupted T-cells, supporting the occurrence of sexual dimorphism in the prevalence of diabetes in NOD in most colonies (4), and showing that SD results in distinct immune outcomes, particularly in terms of the number of cell types. Women usually present a higher prevalence of autoimmune diseases especially during their reproductive years, as evidenced by higher prevalence of systemic lupus erythematosus which may result, in part, from stimulation of the immune system by female hormones (19).

Our data suggest that SD has a negative impact on the immune response, indicating that sleep should be considered a vital part of the immune system. Over the last decades there has been a noticeable reduction in the average amount of sleep and such restriction, whether partial or total, has proved to exert adverse effects on the population afflicted by this condition. Our results indicate that the life-threatening condition induced by either acute or chronic SD is a breakdown of host defense, which is distinctly affected by a previous predisposing factor such as diabetes. This is a relevant issue in its own right, since sleep loss affects general health. However, the inherent stress that results from 
the SD method employed in the current study should also be considered as a relevant component of the overall findings.

The origins of autoimmunity remain unknown; however, it is known that various autoimmune diseases are characterized by a reduction in the number of lymphocytes. Since lymphopenia may facilitate the destructive process that characterizes autoimmunity and that the NOD strain proved to be more susceptible to the effects of SD than the Swiss strain, our results suggest that SD should be considered a risk factor in the onset of autoimmune disorders.

\section{Acknowledgments}

The authors would like to express their cordial thanks to Waldemarks Leite, Alice Lima and Andrea Regina Opperman for assistance during the project.

\section{References}

1. Atkinson MA, Leiter EH. The NOD mouse model of type 1 diabetes: as good as it gets? Nat Med 1999; 5: 601-604.

2. Gleeson PA, Toh BH, Van Driel I. Organ-specific autoimmunity induced by lymphopenia. Immunol Rev 1996; 149: 97-125.

3. King C, llic A, Koelsch K, Sarvetnick N. Homeostatic expansion of T cells during immune insufficiency generates autoimmunity. Cell 2004; 117: 265-277.

4. Fitzpatrick F, Lepault F, Homo-Delarche F, Bach JF, Dardenne M. Influence of castration, alone or combined with thymectomy, on the development of diabetes in the nonobese diabetic mouse. Endocrinology 1991; 129: 1382-1390.

5. Everson CA. Clinical assessment of blood leukocytes, serum cytokines, and serum immunoglobulins as responses to sleep deprivation in laboratory rats. Am J Physiol Regul Integr Comp Physiol 2005; 289: R1054-R1063.

6. Mallon L, Broman JE, Hetta J. High incidence of diabetes in men with sleep complaints or short sleep duration: a 12-year follow-up study of a middle-aged population. Diabetes Care 2005; 28: 27622767.

7. Ayas NT, White DP, Al-Delaimy WK, Manson JE, Stampfer MJ, Speizer FE, et al. A prospective study of self-reported sleep duration and incident diabetes in women. Diabetes Care 2003; 26: 380384.

8. Andersen ML, Martins PJ, D'Almeida V, Bignotto M, Tufik S. Endocrinological and catecholaminergic alterations during sleep deprivation and recovery in male rats. J Sleep Res 2005; 14: 83-90.

9. Velazquez-Moctezuma J, Dominguez-Salazar E, Cortes-Barberena E, Najera-Medina O, Retana-Marquez S, Rodriguez-Aguilera E, et al. Differential effects of rapid eye movement sleep deprivation and immobilization stress on blood lymphocyte subsets in rats. $\mathrm{Neu}$ roimmunomodulation 2004; 11: 261-267.

10. Sleasman JW. The association between immunodeficiency and the development of autoimmune disease. Adv Dent Res 1996; 10: 5761.

11. Miller NE, Bartus RT. Sleep, sleep pathology, and psychopathology in later life: a new research frontier. Neurobiol Aging 1982; 3: 283286.

12. Tufik S, Lindsey CJ, Carlini EA. Does REM sleep deprivation induce a supersensitivity of dopaminergic receptors in the rat brain? Pharmacology 1978; 16: 98-105.

13. Antunes IB, Andersen ML, Baracat EC, Tufik S. The effects of paradoxical sleep deprivation on estrous cycles of the female rats. Horm Behav 2006; 49: 433-440.

14. Spiegel K, Leproult R, Van Cauter E. Impact of sleep debt on metabolic and endocrine function. Lancet 1999; 354: 1435-1439.

15. Everson CA. Sustained sleep deprivation impairs host defense. Am J Physiol Regul Intergr Comp Physiol 1993; 265: R1148-R1154.

16. Ader DN, Johnson SB, Huang SW, Riley WJ. Group size, cage shelf level, and emotionality in non-obese diabetic mice: impact on onset and incidence of IDDM. Psychosom Med 1991; 53: 313-321.

17. Durant S, Coulaud J, Amrani A, El Hasnaoui A, Dardenne M, HomoDelarche $\mathrm{F}$. Effects of various environmental stress paradigms and adrenalectomy on the expression of autoimmune type 1 diabetes in the non-obese diabetic (NOD) mouse. J Autoimmun 1993; 6: 735751.

18. Tochino Y. The NOD mouse as a model of type I diabetes. Crit Rev Immunol 1987; 8: 49-81.

19. McMurray RW. Estrogen, prolactin, and autoimmunity: actions and interactions. Int Immunopharmacol 2001; 1: 995-1008. 